\title{
A Numerical Study on the Transient Response of VVER-1200 Plant Parameters during a Large-break Loss of Coolant Accident
}

\author{
Abid Hossain Khan ${ }^{1 *}$, Md. Ibrahim Al Imran², Nashiyat Fyza ${ }^{3}$ and M. A. R. Sarkar ${ }^{3}$ \\ 'Department of Industrial and Production Engineering, Jashore University of Science and Technology, \\ Jashore-7408, Bangladesh; abid.khan_ipe@just.edu.bd \\ ${ }^{2}$ Department of Electrical and Electronic Engineering, Bangladesh University of Engineering and \\ Technology, Dhaka-1000, Bangladesh; ibrahim.buet.eee@gmail.com \\ 3Department of Mechanical Engineering, Bangladesh University of Engineering and Technology, \\ Dhaka-1000, Bangladesh; fyzanashiyat@gmail.com,drmarsarkar@gmail.com
}

\begin{abstract}
Objectives: To study the transient response of a VVER-1200 based nuclear power plant parameters and safety systems during a Large-break Loss of Coolant Accident (LBLOCA) for two distinct cases; one in which SCRAM is initiated and the other one in which SCRAM is not initiated due to malfunction of the system. Method: Personal Computer Transient Analyzer (PCTRAN) has been used to obtain transient response of the plant for 300 seconds during these accidents. A break of 0.1 $\mathrm{m}^{2}$ size in the hot leg of the primary coolant circuit has been considered in this work. It has also been assumed that off-site AC power supply is completely cut-off for both cases. Findings: Results show that for Loss of Coolant Accident followed by SCRAM, core thermal power drops to only $5 \%$ of the normal operating power within 5 seconds. The peak fuel and cladding temperature is recorded to be slightly higher than $1800^{\circ} \mathrm{C}$ and $610^{\circ} \mathrm{C}$ respectively, showing no failure for any of the two. Maximum pressures inside reactor core structure and reactor containment building are recorded to be 162 bar and 3.5 bar respectively, which are within design limits. However, for Loss of Coolant Accident with no SCRAM, core thermal power is recorded to be around $80 \%$ of the normal operating value after 300 seconds. Peak fuel and cladding temperatures are recorded to be around $2100^{\circ} \mathrm{C}$ and $650^{\circ} \mathrm{C}$ respectively, low enough to avoid failure. Maximum pressure inside reactor core structure is recorded to be 162 bar but pressure inside containment building has risen to around 13.5 bar after 300 seconds time. Applications: PCTRAN is one of the most reliable simulation tools for analyzing a nuclear facility. The results obtained from this study may be used as a reference for designing different components and safety systems of VVER-1200 based nuclear power plants so that the risk of a severe accident is minimized.
\end{abstract}

Keywords: Loss of Coolant Accident, Safety Systems, Transient Response, VVER-1200

\section{Introduction}

Nuclear power plants are believed to be green energy sources due to very low Carbon footprint $\stackrel{1}{\text {. In a world }}$ of growing need of energy, nuclear energy has shown the most potential of being a sustainable one. However, the fear of major or severe accident in a nuclear power plant among common people has somewhat slowed down the flourish of this industry. The panic has been initiated by accidents in recent years such as Chernobyl nuclear accident, Three Mile Island nuclear accident, Fukushima Daiichi nuclear accident, etc. For Three Mile

${ }^{*}$ Author for correspondence 
Island accident in 1979, neither radioactive emission to the atmosphere nor any casualty was recorded. However, it was the first time people got concerned about the safety of a nuclear power plant. This followed by Chernobyl nuclear accident in 1986 which caused death of around 31. People living near the accident site were exposed to radioactive materials, causing death of thousands due to carcinoma $^{2}, \frac{3}{3}$. Fukushima Daiichi nuclear accident in 2011 has made it clear that lack of plant safety features can make a nuclear facility vulnerable during a natural disaster ${ }^{4}$. The large-scale radioactive contamination due to this accident, both in seawater and soil, has created concern among many researchers $\$, 6$. Due to these accidents with long-term consequences, many global communities have continued advocating against nuclear energy. However, due to widespread awareness programs running in different countries, the view of common people has become somewhat positive towards nuclear power in recent times $\stackrel{7-8}{-}$.

In order to prevent accidents with widespread consequences, International Atomic Energy Agency (IAEA) has established safety fundamentals that all member countries should follow ${ }^{9}$. The new GenIII and III+ nuclear power plants are designed to ensure maximum human safety during a Design Based Accident (DBA) or Beyond Design Based Accident (BDBA). VVER-1200 is one of the Gen-III+ pressurized water type nuclear power reactors with improved safety systems. The inherent safety features prevent it from becoming uncontrollable. It has passive safety systems that can operate without external power supply for 72 hours $^{10}$. It also has five levels of safety barriers for preventing release of radioactive materials to the atmosphere during a severe accident. However, there is always a possibility, no matter how small it is, of an unexpected sequence of events or malfunctions of equipment that may lead to undesirable consequences. For emergency preparedness, conducting continuous analyses to evaluate the competence of plant safety systems during unlikely but disastrous sequences of malfunctions is mandatory.

One of the most anticipated and somewhat feared accidents is Loss of Coolant Accident (LOCA). This is a scenario where primary coolant is lost from the reactor due to a break in the coolant line that may result in overheating and subsequent meltdown of the reactor core ${ }^{11}$. Three Mile Island nuclear accident was initiated by LOCA due to leak from a Pressurizer
Relief Valve (PRV) $\stackrel{12}{ }$. Therefore, multiple studies have been conducted to analyze the response of safety systems during LOCA with varying break sizes ${ }^{13}$. A Large-break Loss of Coolant Accident (LBLOCA) is the one in which the break size is greater than $0.1 \mathrm{~m}^{211}$. For smaller break sizes, Small-break Loss of Coolant Accident (SBLOCA) may be initiated. It is more likely that SBLOCA may occur in a nuclear power plant than LBLOCA. Therefore, study on SBLOCA is observed to be more common among the two ${ }^{\underline{14}-18}$. However, there are some studies that have focused on LBLOCA $19-22$.

A basic safety feature of any nuclear reactor is SCRAM (Safety Control Rod Axe Man) where all the control rods are inserted instantaneously during any accident that may lead to core meltdown, such as LOCAs. The design of a nuclear power plant safety system is done in such a manner that it may initiate SCRAM when required, also known as Anticipated Transient with Scram (ATS) ${ }^{11}$. Still, in some cases, it has been observed that SCRAM could not be initiated due to malfunction of the safety systems, also known as Anticipated Transient without Scram (ATWS). Such an event may lead to severe accident if the plant safety systems are not competent enough to back-up the situation, similar to the case of Chernobyl nuclear accident ${ }^{2}$.

Although there are various ways of studying the response of a nuclear facility during an accident, most researchers have preferred numerical methods over experimental ones. The reasons behind their preference are reduced cost, reduced complications reduced possibility of accident and reasonable accuracy of results. While there are many options, Personal Computer Transient Analyzer (PCTRAN) has been one of the most commonly used simulation tools for analyzing the safety aspects of a nuclear facility. PCTRAN may be used to observe the transient response of a nuclear facility during various accident conditions and malfunctions $s^{17}, \underline{22}-\underline{24}$. In this work, a numerical study has been conducted to observe the response of a VVER-1200 based nuclear power plant safety systems during a LBLOCA. Two distinct scenarios were studied; one where SCRAM could be initiated by plant safety systems and the other one where SCRAM could not be initiated due to malfunction of the system. It has also been assumed that off-site power supply is unavailable in order to observe the response of the passive safety systems of VVER-1200 type nuclear power plant. 


\section{Methodology}

In a nuclear power reactor, nuclear power is converted into electricity with the help of steam turbines and generators. The source of this nuclear energy is nuclear fission reaction. The fission chain reaction in a U-235 fuelled nuclear reactor is given by ${ }^{25}$ :

$$
{ }_{92}^{235} U+{ }_{0}^{1} n \rightarrow{ }_{Z_{1}}^{A_{1}} X_{1}+{ }_{Z_{2}}^{A_{2}} X_{2}+\eta \cdot{ }_{0}^{1} n+\text { Energy }
$$

Here $X_{1}$ and $X_{2}$ are reaction products. From each reaction, more than one neutron is obtained on an average (approximately 2.43 for U-235 fuelled reactors). These excess neutrons are necessary to continue subsequent reactions, thus sustaining chain reaction. The increase or decrease in neutron population inside a reactor of finite size may be expressed by effective neutron multiplication factor, keff which is given by ${ }^{25}$ :

$$
k_{\text {eff }}=\frac{\text { Rate of neutron production }}{\text { Rateof neutronabsorption + rateof neutronleakage }}
$$

A reactor is considered critical i.e. its power is steady if $k e f f=1$. If is greater than 1 , the reactor is considered supercritical with increasing power trend and if keff is less than 1 , the reactor is considered sub-critical with decreasing power trend. Sometimes it is more convenient to use reactivity of a reactor, $\rho$ rather than effective neutron multiplication factor, keff from an operator's point of view. The reactivity of a reactor at any given time is denoted by 25 :

$$
\rho=\frac{k_{e f f}-1}{k_{e f f}}
$$

A reactor is critical if $\rho=0$. The reactor is sub-critical when $\rho<0$ and supercritical when $\rho>0$. Reactivity is a unit less quantity. However, different units are used for reactivity such as Dollars (\$) and $\% \Delta \mathrm{k} / \mathrm{k}$. The amount of neutron present inside a reactor is directly dependent on the reactivity inside reactor core at a specific time. Positive reactivity is associated with the reactions taking place in the reactor fuel elements while negative reactivity is associated with the absorption of neutrons in absorber materials and control rods. Positive reactivity may be inserted in a reactor core by withdrawing control rods from reactor core. Similarly, negative reactivity may be inserted by inserting control rods in reactor core. This is why SCRAM is initiated whenever a reactor is on the verge of being prompted critical (uncontrollable).

Apart from the amount of fuel present in the core and the position of control rods, four other parameters influence reactivity inside reactor core; temperature of fuel, temperature of moderator, amount of void present and rate of power generation. The relationships between reactivity and these three parameters are expressed by coefficients of reactivity, which may given by ${ }^{25}$ :

$$
\begin{aligned}
& \alpha_{f}=\frac{\partial \rho}{\partial T_{f}} \\
& \alpha_{m}=\frac{\partial \rho}{\partial T_{m}} \\
& \alpha_{v}=\frac{\partial \rho}{\partial v} \\
& \alpha_{P}=\frac{\partial \rho}{\partial P}
\end{aligned}
$$

Here, $\alpha_{f}$ and $\alpha_{m}$ are temperature coefficients of reactivity for fuel temperature $T_{f}$ and moderator temperature $T_{m}$ respectively. $\alpha_{v}$ is void coefficients of reactivity for void fraction. Also, $\alpha_{p}$ is power coefficients of reactivity for reactor power. The power developed in a thermal nuclear reactor may be given by:

$$
P=E \varphi_{t h} V \sum_{f}
$$

Here $\varphi_{t h}$ is the average neutron flux for thermal neutron, $E$ is the amount of energy released per fission reaction, $V$ is the volume of the core and $\sum_{f}$ is the fission cross-section of the fuel element. For thermal reactors fuelled with U-235, the probability of fission reaction i.e. fission cross-section is the maximum for thermal neutrons having energy near $0.0253 \mathrm{eV}^{25}$. Equation (9) may be differentiated with respect to time to obtain;

$$
\frac{\partial P}{\partial t}=E V \sum_{f} \frac{\partial \varphi_{t h}}{\partial t}
$$

Again, the rate of change of neutron flux is directly proportional to rate of change of neutron population, as shown in Equation (11) 25 . 


$$
\frac{\partial n}{\partial t}=\frac{1}{v} \frac{\partial \varphi_{t h}}{\partial t}
$$

Also, rate of change of neutron population is proportional to the amount of reactivity inserted or withdrawn from reactor core. As a result, power developed in a reactor increases with increase in positive reactivity while it decreases with negative reactivity.

SCRAM is one of the main emergency responses of the plant to prevent uncontrollable reactor operation. However, SCRAM may not be initiated by plant safety systems due to malfunctions. Therefore, other options should always be there to ensure safety of a nuclear facility. VVER-1200 based nuclear power plants are provided with numerous safety systems, both active and passive type. The passive safety systems are provided in order to ensure safe handling of plant during Station Blackout (SBO). Also, because of being a Pressurized Water Reactor (PWR), VVER-1200 nuclear reactors have two inherent safety features that should prevent sudden rise of power during accidents like LBLOCA. These two inherent safety features are ${ }^{26}$ :

$>$ Negative power coefficient of reactivity, which selfregulates reactivity inside the core during sudden increase in reactor power.

$>$ Negative void coefficient, which allows reactivity to decrease in absence of coolant, thus reducing power.

In this work, the response of plant safety systems of a VVER-1200 based nuclear power plant during a LBLOCA has been investigated with the help of Personal Computer Transient Analyzer (PCTRAN). PCTRAN has been developed by Micro Simulation Technology Inc., USA for transient analysis of different nuclear facilities during accident scenarios. In this work, demo version of PCTRAN has been used which can give transient response of the plant for 300 seconds. However, this time limit is sufficient for this study sine most plant safety systems start acting within 5-50 seconds. It has different modules for different power plant types. The PCTRAN module for VVER-1200 is shown in Figure 1.

A large break of $0.1 \mathrm{~m}^{2}$ in the hot leg of the A loop of primary coolant circuit has been considered in this study. Analysis for cold leg break has not been conducted since the response for both hot leg break and cold leg break has

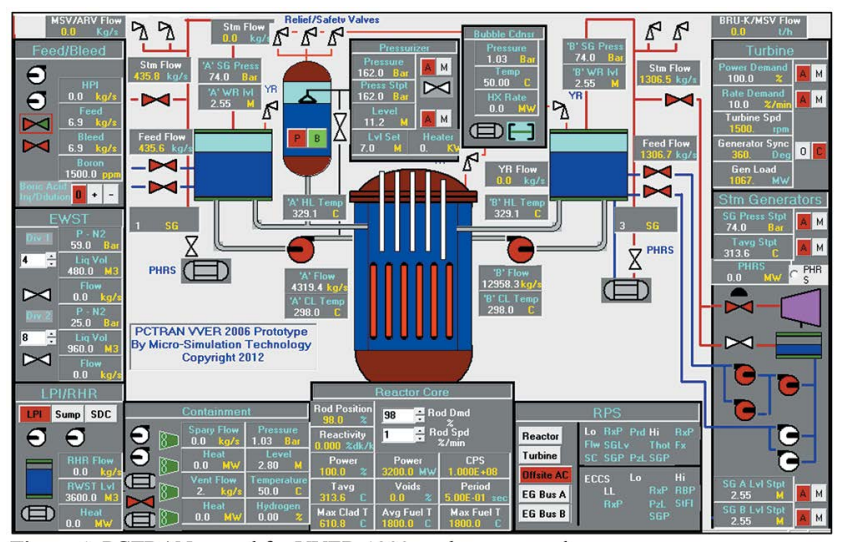

Figure 1. PCTRAN consol for VVER-1200 nuclear power plant.

been found to be almost identical in available literature ${ }^{17}$. Two different cases of accident have been considered in this study; one in which SCRAM could be initiated by plant safety systems and the other one in which no SCRAM could be initiated due to malfunction. Also, it has been considered that the external power supply was completely cut-off from the beginning of the analysis so that the response of different passive safety systems could be observed for SBO condition. For both cases, data were recorded from the moment the break emerged in the hot leg of the primary coolant circuit.

After obtaining the simulation results, the transient response data of different thermal hydraulic and other important parameters of the plant are plotted against time. Different important plant parameters considered in this study have been presented in Table 1 . The sequence of activation of the plant safety systems has also been studied. Finally, the possibility of major damage to any of the components of the nuclear power plant has been evaluated in accordance with the acceptance criteria specified by IAEA ${ }^{27}$. The acceptance criteria are:

- The fuel cladding temperature should not exceed $1480^{\circ} \mathrm{C}$ in order to prevent cladding embrittlement and failure.

- There should be no fuel meltdown.

- The pressure inside reactor pressure vessel should not exceed $135 \%$ of the design value for ATWS and $110 \%$ for other DBAs.

- The calculated peak containment pressure should be lower than containment design pressure. 
Table 1. Plant parameters during normal operating condition

\begin{tabular}{|l|c|}
\hline \multicolumn{1}{|c|}{ Plant Parameters } & Operating Value \\
\hline Nominal Core Thermal Power & $3200 \mathrm{MW}$ \\
\hline $\begin{array}{l}\text { Nominal Pressure inside Reactor } \\
\text { Core Structure }\end{array}$ & $162.0 \mathrm{bar}$ \\
\hline $\begin{array}{l}\text { Nominal Pressure inside Reactor } \\
\text { Containment Building }\end{array}$ & $1.03 \mathrm{bar}$ \\
\hline $\begin{array}{l}\text { Average Primary Coolant } \\
\text { Temperature }\end{array}$ & $313 .^{\circ} \mathrm{C}$ \\
\hline $\begin{array}{l}\text { Maximum Cladding Temperature } \\
\text { Maximum Fuel Temperature }\end{array}$ & $610.8^{\circ} \mathrm{C}$ \\
\hline $\begin{array}{l}\text { Reactor Containment Building } \\
\text { Temperature }\end{array}$ & $1800^{\circ} \mathrm{C}$ \\
\hline $\begin{array}{l}\text { Departure from Nucleate Boiling } \\
\text { Ratio (DNBR) }\end{array}$ & $50^{\circ} \mathrm{C}$ \\
\hline $\begin{array}{l}\text { Boron Concentration in Primary } \\
\text { Coolant }\end{array}$ & $1500.0 \mathrm{ppm}$ \\
\hline
\end{tabular}

\section{Results and Discussion}

\subsection{LBLOCA with SCRAM}

Initially, a transient simulation of LBLOCA accident in a VVER-1200 type nuclear power plant is conducted assuming that there is no malfunction in the SCRAM initiating system of the plant. As a result, SCRAM was initiated as soon as coolant started escaping from the large break and temperature of the reactor core elements started increasing rapidly. The transient report of the plant just after the emergence of the large break in the hot leg is presented below:

$>4.0$ seconds: Due to rapid temperature and pressure rise inside Reactor Containment Building (RCB), Containment spray starts at 1.3 bar pressure. Also, Containment Vent Valve (CVV) is closed in order to avoid release radioactive air from containment to the atmosphere.

$>7.5$ seconds: Reactor SCRAM is initiated due to rapid increase in core reactivity and core thermal power. Also, Turbine trip is observed due to fall of steam supply.

$>8.0$ seconds: Turbine Bypass Valve is opened to bypass steam.
17.0 seconds and 22.5 seconds: Steam Generator (SG) Safety Relief Valves (SRVs) are opened to reduce steam pressure.

$>27.0$ seconds and 40.0 seconds: SG SRVs are closed.

$>48.5$ seconds: Feed Water Isolation Valves (FWIVs) are closed to cut-off water supply to SG.

$>52.5$ seconds: Accumulator Valve \#1 opens at 59.0 bar pressure to inject boron inside Reactor Core Structure (RCS) in order to bring positive reactivity down.

$>70.0$ seconds: Accumulator Valve \#2 opens to re-flood RCS.

From the transient report, it may be observed that Containment Vent Valve (CVV) is closed as radioactive coolant came in direct contact with air inside the Reactor Containment Building (RCB). As a result, the possibility of contamination of surrounding atmosphere is quite negligible unless the RCB itself fails due to pressure rise. To keep the pressure and temperature inside RCB in a controlled state and avoid containment failure, containment spray system is also activated. SCRAM is initiated within 7.5 seconds from the initiation of LOCA, thus the power generated in the reactor core is reduced considerable. This event is followed by turbine trip and bypass of steam from turbine through bypass valve. Steam generator Safety Relief Valves (SRVs) is activated in order to avoid pressure build-up inside steam generator. They were also closed as soon as the rate of steam generation became sufficiently low. After that, steam generator feed water supply is completely cut-off to stop steam generation. Finally, Accumulator is activated in two stages; one at high pressure (59.0 bar) to inject boron inside reactor core and bring reactivity down further and the other one at comparatively lower pressure to restore coolant inside Reactor Core Structure (RCS).

The change in core thermal power with time for LBLOCA followed by SCRAM is shown in Figure 2(a). From Figure 2(a), it may be observed that the peak core thermal power is around $105 \%$ of the normal operating value but it is immediately brought down due to negative reactivity insertion by SCRAM. As a result, reactor core thermal power drops sharply to less than $5 \%$ in just 50 seconds time. In order to reduce reactivity further, boron injection system is also activated at 52.5 seconds time. Therefore, unregulated power generation is not observed and subsequent heating of core elements is avoided. The change in temperature of different components of the nuclear reactor and containment building with respect to 
time is shown in Figure 2(b). From Figure 2(b), it may be observed that the peak temperatures of fuel pellet and fuel cladding are recorded to be slightly higher than the value during normal operating condition. As a result, no fuel meltdown or cladding failure is observed. However, an interesting observation is that the temperature inside the reactor containment building has risen to a value more than $100^{\circ} \mathrm{C}$. Therefore, there is a possibility of loss of human life if a person is accidentally trapped inside the containment structure.

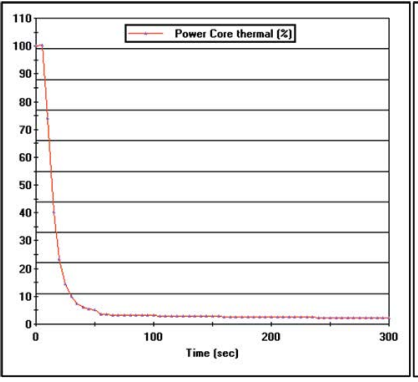

(a)

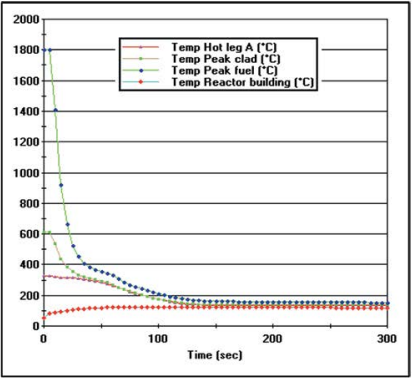

(b)
Figure 2. Change in (a) Core thermal power and (b) Temperature of different components of the plant with time for LBLOCA with SCRAM.

The change in rate of loss of coolant from break area with time is shown in Figure 3(a). From Figure 3(a), it may be observed that initially the rate of coolant loss is raised rapidly to a value just above $7000 \mathrm{~kg} / \mathrm{s}$ due to high pressure of the primary coolant loop. However, a quick decrease in this rate is observed as soon as SCRAM is initiated. The reason behind this is that the rate of power generation in reactor core started coming down due to SCRAM, reducing the temperature and thus pressure of the coolant system. Again, rapid loss of coolant also contributed to further decrease in pressure. However, the flow rate of coolant through break area started rising again due to the activation of Accumulator. After fluctuating for a few seconds, a steady flow rate of around $500 \mathrm{~kg} / \mathrm{s}$ is observed as the accumulator pressure started decreasing. The change in flow rate of Emergency Core Cooling System (ECCS) and High Pressure Injector (HPI) with respect to time is shown in Figure 3(b). Finally, the change in water level inside reactor core structure is shown in Figure 3(c). From Figure 3(c), it may be observed that the coolant water level inside reactor core structure started going down after a time delay of around 30 seconds. This is because of the fact that Pressurizer accommodates a large quantity of coolant and the core water level started going down only after the Pressurizer was completely emptied. The level again started going up due to the activation of ECCS and HPI at 52.5 seconds time. The reactor core was completely re-flooded within 110 seconds. After that, ECCS and HPI only kept supplying water equal to the amount lost from break area.

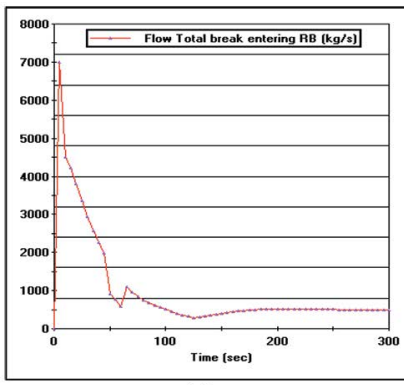

(a)

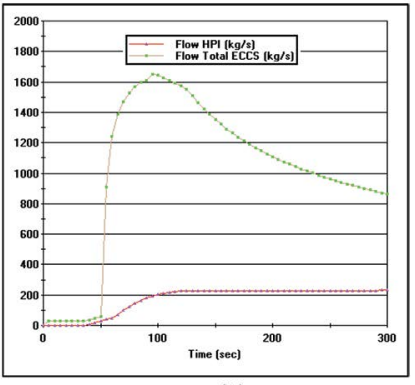

(b)

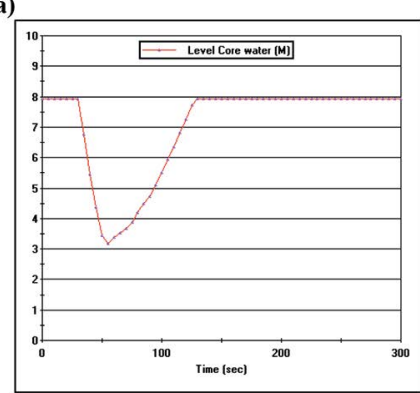

(c)

Figure 3. Change in (a) Flow through break area, (b) Flow rate of emergency cooling systems and (c) Core water level with time for LBLOCA with SCRAM.

The change in void fraction inside RCS with time is shown in Figure 4(a). From Figure 4(a), it may be observed that the amount of void inside RCS reached a peak value of $73 \%$ in 52.5 seconds time. It gradually came down to $0 \%$ in less than 200 seconds because of the activation of ECCS. The change in Departure from Nucleate Boiling Ratio (DNBR) with time is presented in Figure 4(b). From Figure 4(b), it may be observed that DNBR has not fallen considerably from its normal operating value, which should be near 1.5 for PWR. As a result, there should be no risk of sudden increase in heat flux in fuel elements due to reduction in heat transfer coefficient of coolant.

The change in pressure inside RCS with time is shown in Figure 5(a). From Figure 5(a), it may be observed that RCS pressure has fallen down right after the break has emerged. This reduction is basically due to loss of coolant from the break area. However, after SCRAM, there is a sudden increase in pressure due to reduction in coolant 


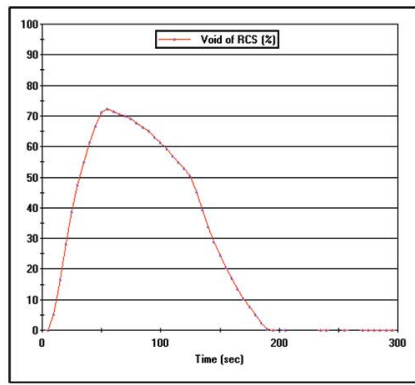

(a)

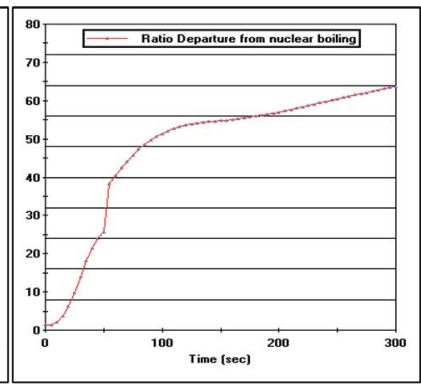

(b)
Figure 4. Change in (a) Void fraction and (b) DNBR with time for LBLOCA with SCRAM.

flow area due to control rod insertion. This again started going down as soon as the flow got adjusted with the situation. Finally, the pressure became somewhat steady due to injection of coolant water from ECCS. The pressure inside RCB has never crossed the acceptance value of $110 \%$ for Design Based Accident (DBA). So, it may be stated that the integrity of RCS should be unaffected. The change in pressure in Reactor Containment Building (RCB) with time is shown in Figure 5(b). From Figure 5(b), it may be observed that RCB pressure has initially increased due to vaporization of hot coolant in a comparatively low pressure atmosphere. Nevertheless, the pressure has never crossed 3.5bar, which is well below the design pressure, which is near 4.2 bar for plants operating in USA ${ }^{28}$. The design parameters for Russian VVER-1200 type nuclear power plant may be different. Still, the possibility of RCB failure may also be omitted.

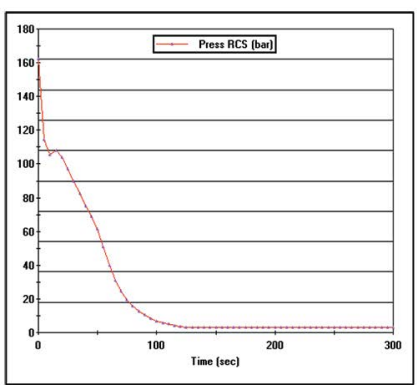

(a)

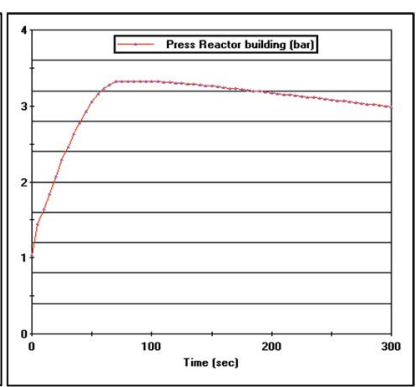

(b)
Figure 5. Change in (a) RCS pressure and (b) RCB pressure with time for LBLOCA with SCRAM.

The change in boron concentration in RCS with time is shown in Figure 6(a). From Figure 6(a), it may be observed that boron concentration inside RCS has started increasing after 52.5 seconds time. This is due to the activation of HPI of the core cooling system. Therefore, the reactivity of coolant leaking out from the containment building should be reduced considerably. The change in reading of radiation monitor at different locations of the plant with time is presented in Figure 6(b). From Figure 6(b), it may be observed that the activity level of air inside RCB has increased gradually due to mixing of leaking coolant with containment air. However, the activity level is quite low, much lower than 1 CPM (Count Per Minute). Nevertheless, there is small possibility of radiation hazard if a person is exposed to this radiation for a long duration. The activity level inside auxiliary building air has been steady, which is basically background radiation. Therefore, it may be assumed that there is no release of radioactive air from reactor containment building to auxiliary building or surrounding atmosphere.

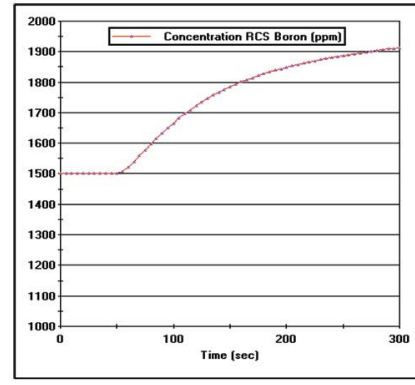

(a)

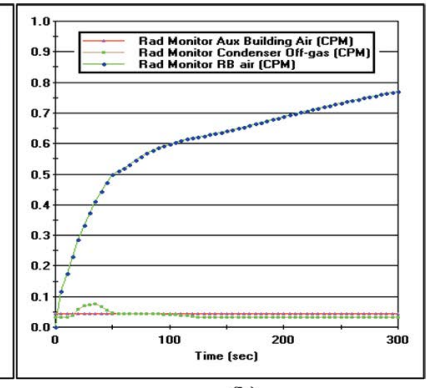

(b)
Figure 6. Change in (a) Boron concentration inside RCS and (b) Radiation monitor reading at different plant locations with time for LBLOCA with SCRAM.

From the above results, it may be opined that the plant safety systems are capable of managing LBLOCA situation if SCRAM is available.

\subsection{LBLOCA without SCRAM}

After obtaining the transient response for LBLOCA with SCRAM, another transient simulation of LBLOCA accident is conducted assuming that SCRAM is not initiated due to sudden malfunction in the safety system of the plant. The transient report of the plant is presented below:

$>4.0$ seconds: Due to rapid temperature and pressure rise inside the Reactor Containment Building ( $\mathrm{RCB})$, Containment spray starts at 1.3 bar pressure. Also, Containment Vent Valve (CVV) is closed in order to avoid release radioactive air from containment to 
the atmosphere. Emergency Core Cooling System (ECCS) is initiated.

$>73.5$ seconds: Main Steam Isolation Valve (MSIV) is closed.

$>217.0$ seconds: Fan Cooler starts at 10.0 bar to cool down air and reduce pressure inside the RCB.

From the transient report, it may be observed that multiple safety sequences observed for previous case are absent due to unavailability of SCRAM. Turbine trip and Steam Generator (SG) shutdown are not initiated since the core thermal power is high and the secondary coolant circuit has to continue working to remove this heat from primary coolant circuit. High Pressure Injector (HPI) is only activated for a few seconds since the primary coolant system pressure is much higher than the operating pressure of HPI (59.0 bar). As a result, boron injection is almost absent in this case.

For LBLOCA without SCRAM, only containment spray system was initiated like before in order to cool down the air and reduce pressure inside RCB. Containment vent valve is also closed like before. An interesting response by the plant safety systems in this case is that MSIV is closed to prevent steam isolation from the steam generator. Another safety response which is not observed for the previous accident scenario is the initiation of fan cooler in order to reduce pressure inside containment building. This is because of the fact that pressure inside RCB has never reached the threshold level for fan cooler to be initiated in the previous situation as it does in this case.

The change in core thermal power with time for LBLOCA without initiation of SCRAM is shown in Figure 7(a). From Figure 7(a), it may be observed that the peak core thermal power around $128 \%$ of the normal operating value, which is still in acceptable range. However, core thermal power has dropped to only $80 \%$ of the normal operating value in 300 seconds, which is much slower than the previous case. Also, the rate of heat generation is much higher. The change in temperature of different components of the nuclear reactor and containment building with respect to time is shown in Figure 7(b). From Figure 7(b), it may be observed that the peak temperatures of fuel pellet and fuel cladding are recorded to be nearly $2100^{\circ} \mathrm{C}$ and $650^{\circ} \mathrm{C}$ respectively. As a result, no fuel meltdown or cladding failure is expected to occur since they are both lower than maximum acceptance values. However, temperature inside RCB has risen to $200^{\circ} \mathrm{C}$, which may cause loss of human life if anyone is trapped inside. The temperature of air inside RCB is much higher than before, indicating that the pressure inside RCB should also be higher than that obtained in the previous case.

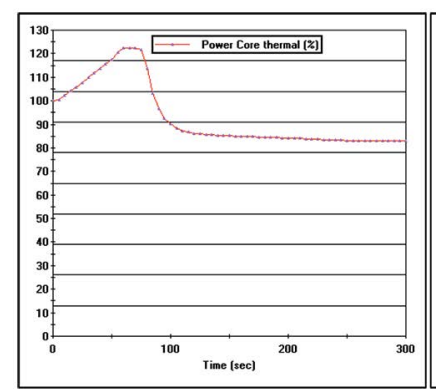

(a)

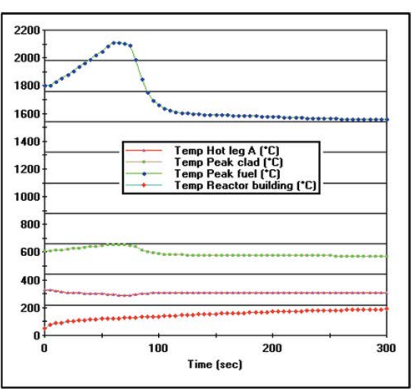

(b)
Figure 7. Change in (a) Core thermal power and (b) Temperature of different components of the plant with time for LBLOCA without SCRAM.

The change in rate of loss of coolant from break area with time is shown in Figure 8(a). From Figure 8(a), it may be observed that initially the rate of coolant loss is raised rapidly to a value just above $7000 \mathrm{~kg} / \mathrm{s}$ just like the previous case. However in this case, the rate of decrease in flow rate is much slower than before. The logic behind this is that SCRAM was not initiated and core heat generation is high all the way through. The only thing that has reduced the rate of heat generation is the negative void coefficient of the reactor. A steady flow rate of around $1800 \mathrm{~kg} / \mathrm{s}$ is observed after a few seconds, much higher than the previous case. The change in flow rate of ECCS and HPI with respect to time is shown in Figure 8(b). From Figure 8(b), it may be observed that HPI is almost inactive during this event. The flow rate of ECCS is also very low, only $27 \mathrm{~kg} / \mathrm{s}$ during steady condition. This flow rate is not enough to compensate for the coolant leaking from the break area. Therefore, void formation is almost certain in this case. Finally, the change in water level inside reactor core structure is shown in Figure 8(c). From Figure 8(c), it may be observed that the level of water in liquid state is zero within 70 seconds from initiation of LBLOCA, which is alarming. However, this should bring down the rate of heat generation slightly due to absence of moderator around reactor core, which is exactly what observed in Figure 7(a).

The change in void fraction inside RCS with time is shown in Figure 9(a). From Figure 9(a), it may be observed that the amount of void inside RCS has become $100 \%$ in just 100 seconds time and this amount has not 
been reduced throughout the event. The change in DNBR with time is presented in Figure 9(b). From Figure 9(b), it may be observed that DNBR has fallen down to 1.0 in just 50 seconds, indicating film boiling afterwards. The value has fallen even further and has approached 0 , which is an alarming situation. Luckily, no cladding or fuel failure was recorded.

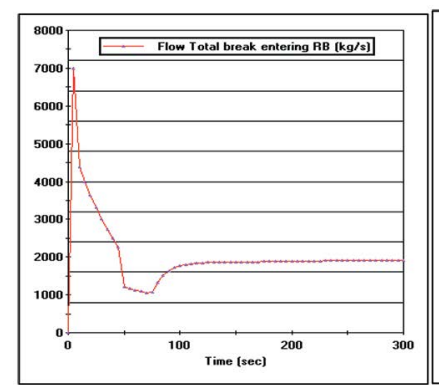

(a)

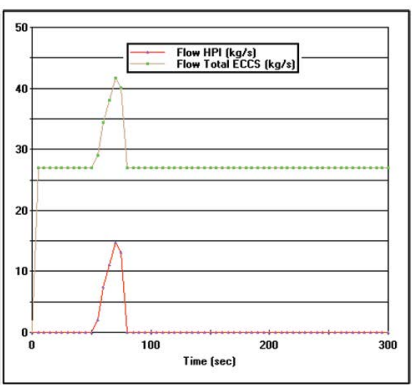

(b)

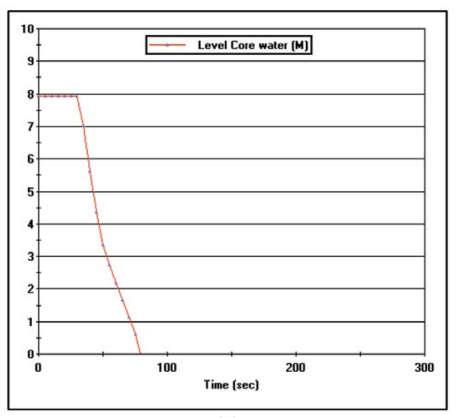

(c)

Figure 8. Change in (a) Flow through break area, (b) Flow rate of emergency cooling systems and (c) Core water level with time for LBLOCA without SCRAM.

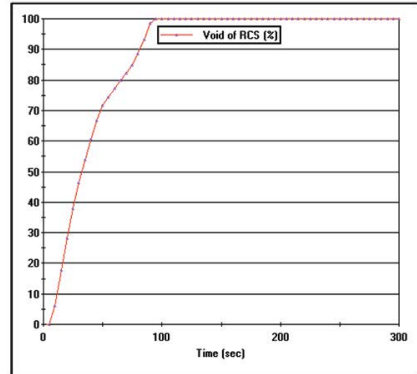

(a)

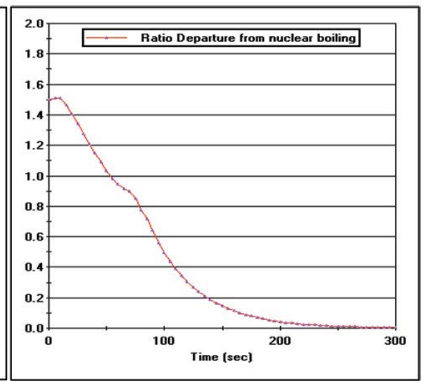

(b)
Figure 9. Change in (a) Void Fraction and (b) DNBR with Time for LBLOCA without SCRAM.

The change in pressure inside RCS with time is shown in Figure 10(a). From Figure 10(a), it may be observed that RCS pressure response is almost similar to the previous case and the pressure inside RCB has not crossed the acceptance value of $135 \%$ for Anticipated Transient without Scram (ATWS). So, it may be stated that the integrity of RCS should be unaffected in this situation too. The change in pressure in RCB with time is shown in Figure 10(b). From Figure 10(b), it may be observed that RCB pressure has continuously increased, unlike previous case. The explanation behind this is that the rate of coolant leaking through the break has much higher flow rate and enthalpy than the previous situation. As a result, pressure buildup inside RCB is much higher, reaching a value higher than 13.5 bar in just 300 seconds. The initiation of containment spray system and fan cooler are not sufficient enough to manage this situation. Therefore, further analysis is necessary to find suitable safety solutions. Also, the design of the RCB should be done keeping this scenario in mind.

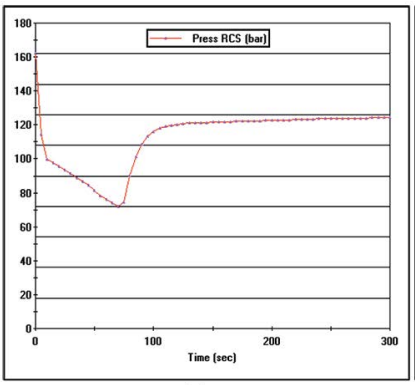

(a)

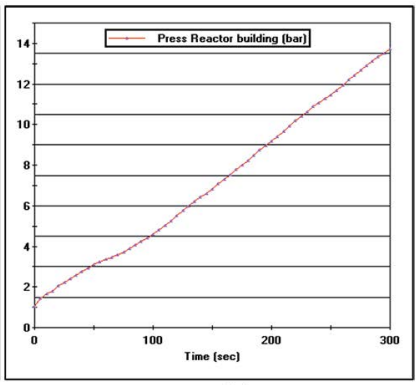

(b)
Figure 10. Change in (a) RCS pressure and (b) RCB pressure with time for LBLOCA without SCRAM.

The change in boron concentration in RCS with time is shown in Figure 11(a). From Figure 11(a), it may be observed that boron concentration has remained constant throughout this event since HPI was barely active in this case. The change in reading of radiation monitor at different locations of the plant with time is presented in Figure 11(b). From Figure 11(b), it may be observed that the activity level of air inside RCB has increased in a steady rate to around 2.5 CPM in 300 seconds. This is significantly higher than the previous case and possibility of human health hazard is also higher. The activity level inside auxiliary building air has only indicated background radiation. Therefore, no leakage of radioactive air to auxiliary building or surrounding atmosphere is observed, just like the previous case. 


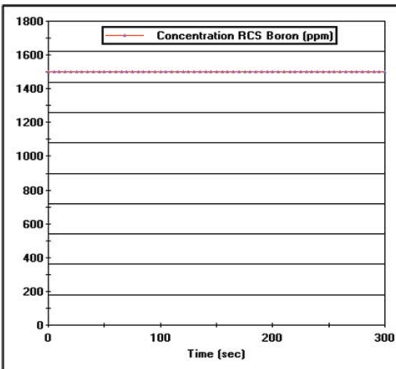

(a)

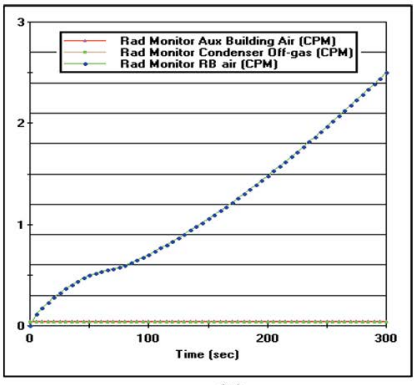

(b)
Figure 11. Change in (a) Boron concentration inside RCS and (b) Radiation monitor reading at different plant locations with time for LBLOCA without SCRAM.

From the above results, it may be stated that even without SCRAM initiation, plant safety systems have been capable of preventing failure of reactor core elements. However, film boiling is observed inside the core, which should not be overlooked. Also, the pressure buildup inside RCB is very rapid and there is a strong possibility of burst-out of RCB due to excessive pressure if not designed properly. As a result, there is a risk of contamination of the surroundings with radioactive elements, which should be prevented at any cost.

\section{Conclusion}

In this work, the transient response of a VVER-1200 based nuclear power plant safety systems during a Large-break Loss of Coolant Accident (LBLOCA) with a break of $0.1 \mathrm{~m}^{2}$ size in the hot leg of the primary coolant circuit has been investigated. Personal Computer Transient Analyzer (PCTRAN) has been used for obtaining the transient response of the plant. Simulations were run for two situations; one in which SCRAM is initiated by the plant safety system and the other one in which SCRAM could not be initiated due to malfunction. Also, off-site AC power supply is completely cut-off in order to observe the response of the passive safety systems.

Results indicate that LBLOCA with SCRAM, core thermal power drops within 5 seconds due to negative reactivity insertion by control rods. The peak fuel and cladding temperatures are recorded to be around $1800^{\circ} \mathrm{C}$ and $610^{\circ} \mathrm{C}$ respectively, which are not high enough to cause fuel meltdown or cladding failure. Temperature inside the reactor containment building has reached a value greater than $100^{\circ} \mathrm{C}$ in 300 seconds, showing possibility of human life loss. DNBR has always been above 1.5, preventing film boiling of the coolant. The amount of void inside RCS reached a peak value of $73 \%$ in 52.5 seconds time and gradually came down to $0 \%$ in less than 200 seconds. Maximum pressures inside reactor core structure and reactor containment building are recorded to be around 162 bar and 3.5 bar respectively, showing no sign of failure for either of the two. The activity level inside RCB is lower than 1 CPM. Finally, no event like release of radioactive air from reactor containment building to auxiliary building or surrounding atmosphere was recorded.

For LBLOCA with no SCRAM, core thermal power is recorded to be around $128 \%$ of the normal operating value. It has always been higher than $80 \%$ of the normal operating value for the 300 seconds time duration. Peak fuel and cladding temperatures are recorded to be around $2100^{\circ} \mathrm{C}$ and $650^{\circ} \mathrm{C}$ respectively, thus no failure of fuel element or cladding is observed. The amount of void inside RCS has become $100 \%$ in 100 seconds time. DNBR has fallen down to 1.0 in 50 seconds, indicating film boiling of the coolant water. However, no cladding or fuel failure was recorded. Maximum pressure inside RCS is recorded to be 162 bar, which is within acceptable limit. Pressure inside RCB has risen to around 13.5 bar after 300 seconds time, which may cause burst-out of RCB. Proper designing is necessary to avoid the situation. Finally, the activity level of air inside RCB has reached a value of 2.5 CPM in 300 seconds. No leakage of radioactive air to auxiliary building or surrounding atmosphere is observed in case of this type of accident also.

The above study has focused only on the safety aspects of a VVER-1200 type nuclear power plant. Safety response of other types of power plants may also be investigated. Also, other break sizes may be studied. Finally, the study has generated transient response data for only 300 seconds time due to the limitations of demo version of PCTRAN. This study may be extended for larger time duration for getting a clearer picture of the situation.

\section{Acknowledgement}

The authors would like to thank Micro Simulation Technology Inc., USA for developing PCTRAN as a transient analysis tool for VVER-1200 nuclear power reactor. 


\section{Conflict of Interest}

The authors declare no conflict of interest.

\section{References}

1. Roth MB, Jaramillo P. Going nuclear for climate mitigation: An analysis of the cost effectiveness of preserving existing US nuclear power plants as a carbon avoidance strategy. Energy. 2017; 131:67-77. https://doi.org/10.1016/j. energy.2017.05.011

2. Baverstock K, Williams D. The Chernobyl accident 20 years on: An assessment of the health consequences and the international response. Environmental Health Perspectives. 2006; 114(9):1312-7. PMid: 16966081 PMCid: PMC1570049. https://doi.org/10.1289/ehp.9113

3. Kortov V, Ustyantsev Y. Chernobyl accident: Causes, consequences and problems of radiation measurements. Radiation Measurements. 2013; 55:12-6. https://doi.org/10.1016/j.radmeas.2012.05.015

4. Khan AH, Hasan S, Sarkar MAR. Analysis of possible causes of Fukushima disaster. International Journal of Nuclear and Quantum Engineering. 2018; 12(2):53-8.

5. Buesseler K, Aoyama M, Fukasawa M. Impacts of the Fukushima nuclear power plants on marine radioactivity. EnvironmentalScienceandTechnology.2011;45(23):9931-5. PMid: 22013920. https://doi.org/10.1021/es202816c

6. Yasunari TJ, Stohl A, Hayano RS, Burkhart JF, Eckhardt S, Yasunari T. Cesium-137 deposition and contamination of Japanese soils due to the Fukushima nuclear accident. Proceedings of the National Academy of Sciences. 2011; 108(49):19530-4. PMid: 22084074 PMCid: PMC3241755. https://doi.org/10.1073/pnas.1112058108

7. Goodfellow MJ, Dewick P, Wortley J, Azapagic A. Public perceptions of design options for new nuclear plants in the UK. Process Safety and Environmental Protection. 2015; 94:72-88. https://doi.org/10.1016/j.psep.2014.12.008

8. Bisconti AS. Changing public attitudes toward nuclear energy. Progress in Nuclear Energy. 2018; 102:103-13. https://doi.org/10.1016/j.pnucene.2017.07.002

9. Principles IF. Safety fundamentals. IAEA Safety Standards Series SF-1. International Atomic Energy Agency: Vienna, Austria; 2006. p. 1-37.

10. Asmolov VG, Gusev IN, Kazanskiy VR, Povarov VP, Statsura DB. New generation first-of-the kind unit-VVER-1200 design features. Nuclear Energy and Technology. 2017; 3(4):260-9. https://doi.org/10.1016/j.nucet.2017.10.003

11. Joyce M. Nuclear engineering: A Conceptual Introduction to Nuclear Power. Butterworth-Heinemann. 2017.

12. Perrow C. Normal accident at Three Mile Island. Society. 1981; 18(5):17-26. https://doi.org/10.1007/BF02701322
13. Chatterjee B, Mukhopadhyay D, Lele HG, Ghosh AK, Kushwaha HS, Groudev P, Atanasova B. Analyses for VVER-1000/320 reactor for spectrum of break sizes along with SBO. Annals of Nuclear Energy. 2010; 37(3):359-70. https://doi.org/10.1016/j.anucene.2009.12.005

14. Bae H, Kim DE, Ryu SU, Yi SJ, Park HS. Comparison of three small-break loss-of-coolant accident tests with different break locations using the system-integrated modular advanced reactor-integral test loop facility to estimate the safety of the smart design. Nuclear Engineering and Technology. 2017; 49(5):968-78. https://doi.org/10.1016/j. net.2017.04.006

15. Jobst M, Wilhelm P, Kozmenkov Y, Kliem S. Severe accident management measures for a generic German PWR. Part II: Small-break loss-of-coolant accident. Annals of Nuclear Energy. 2018; 122:280-96. https://doi.org/10.1016/j. anucene.2018.08.017

16. Hong SH, Kang S, Kim J, Park JK, Moon SK. Reflood experiments at elevated pressures using intact and deformed rod bundles to simulate small and medium break loss-of-coolant accidents. Nuclear Engineering and Design. 2018; 338:209-17. https://doi.org/10.1016/j. nucengdes.2018.08.017

17. Fyza N, Hossain A, Sarkar R. Analysis of the thermalhydraulic parameters of VVER-1200 due to loss of coolant accident concurrent with loss of offsite power. Energy Procedia. 2019; 160:155-61. https://doi.org/10.1016/j. egypro.2019.02.131

18. Pawluczyk M, Mazgaj P, Gurgacz S, Gatkowski M, Darnowski P. Loss of coolant accident in pressurized water reactor. Prediction of a 6-inch cold leg break with Relap5 and Cathare 2. Procedia Engineering. 2016; 157:333-40. https://doi.org/10.1016/j.proeng.2016.08.374

19. Queral C, Montero-Mayorga J, Gonzalez-Cadelo J, Jimenez G. AP1000 Large-break LOCA BEPU analysis with TRACE code. Annals of Nuclear Energy. 2015; 85:576-89. https://doi.org/10.1016/j.anucene.2015.06.011

20. Rahgoshay M, Hashemi-Tilehnoee M. Pressure distribution in the containment of VVER-1000 during the first seconds of large break LOCA. Progress in Nuclear Energy. 2016; 88:211-7. https://doi.org/10.1016/j.pnucene.2016.01.010

21. Bezrukov YA, Schekoldin VI, Zaitsev SI, Churkin AN, Lisenkov EA. A study of different cases of VVER reactor core flooding in a large break loss of coolant accident. EPJ Nuclear Sciences and Technologies. 2016; 2(3):1-11. https://doi.org/10.1051/epjn/e2015-50005-9

22. Ibrahim SJ, Ewim DR, Edeoja OA. Simulation of safety and transient analysis of a pressurized water reactor using the personal computer transient analyzer. Leonardo Electronic Journal of Practices and Technologies. 2013; 22:93-105. 
23. Mollah AS. PCTRAN: Education tool for simulation of safety and transient analysis of a pressurized water reactor. International Journal of Integrated Sciences and Technology. 2018; 3:1-10.

24. Saha A, Fyza N, Hossain A, Sarkar MR. Simulation of tube rupture in steam generator and transient analysis of VVER1200 using PCTRAN. Energy Procedia. 2019; 160:162-9. https://doi.org/10.1016/j.egypro.2019.02.132

25. Applied Reactor Technology. 2011. https://www. semanticscholar.org/paper/Applied-Reactor-TechnologyAnglart/94d1fedc054e3eeb080a849c2cebe813946d72d4
26. Advanced Reactors Information System (ARIS). 2006. https://www.iaea.org/publications/reports/annualreport-2006

27. Accident analysis for nuclear power plants with pressurized water reactors. IAEA Safety Report Series No. 3. International Atomic Energy Agency: Vienna, Austria; 2003. p. 1-77.

28. Hossain M, Khan AH, Sarkar MAR. A numerical approach for designing the primary containment building of a pressurized water reactor. Transactions of American Nuclear Society. 2018; 118:809-10. 